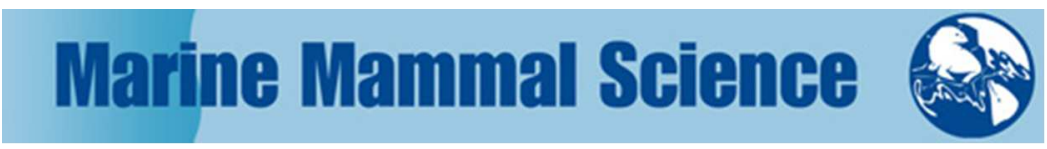

\title{
Improved estimates of digestion correction factors and passage rates for harbor seal (Phoca vitulina) prey in the NE Atlantic
}

\begin{tabular}{|r|l|}
\hline Journal: & Marine Mammal Science \\
\hline Manuscript ID & MMSCI-4305.R2 \\
\hline Danuscript Type: & Article \\
\hline Complete List of Authors: & $\begin{array}{l}\text { Wilson, Lindsay; University of St. Andrews, Sea Mammal Research Unit, } \\
\text { Scottish Oceans Institute } \\
\text { Grellier, Kate; University of St. Andrews, Sea Mammal Research Unit, } \\
\text { Scottish Oceans Institute; Natural Power Consultants, Ochill House, } \\
\text { Springkerse Business Park } \\
\text { Hammond, Philip; University of St Andrews, Sea Mammal Research Unit, } \\
\text { Scottish Oceans Institute }\end{array}$ \\
\hline Keywords: & $\begin{array}{l}\text { digestion, digestion correction factor, digestion coefficient, recovery rate, } \\
\text { passage rate, harbor seal, diet, prey, otolith, beak }\end{array}$ \\
\hline & \\
\hline
\end{tabular}

SCHOLARONE

Manuscripts 


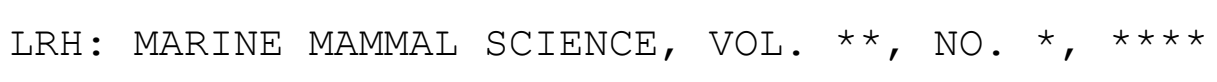

RRH: WILSON ET AL.: DIGESTION CORRECTION FACTORS

Improved estimates of digestion correction factors and passage rates for harbor seal (Phoca vitulina) prey in the northeast Atlantic

LINDsAY J. WILson, ${ }^{1}$ Sea Mammal Research Unit, Scottish Oceans Institute, University of St Andrews, Fife KY16 8LB, Scotland; Kate Grellier ${ }^{1,2}$, Sea Mammal Research Unit, Scottish Oceans Institute, University of St Andrews, Fife KY16 8LB, Scotland and Natural Power Consultants, Ochil House, Springkerse Business Park, Stirling FK7 7XE, Scotland; Philip S. HAMmond, Sea Mammal Research Unit, Scottish Oceans Institute, University of st Andrews, Fife KY16 8LB, Scotland. 
$[4305]-2$

ABSTRACT

Diet composition in pinnipeds is widely estimated using hard prey remains recovered from feces. To estimate the size and number of prey represented in fecal samples accurately, digestion correction factors (DCFS) must be applied to measurements and counts of fish otoliths and cephalopod beaks. In this study, 101 whole prey feeding trials were conducted with six harbor seals (Phoca vitulina) and 18 prey species. We derived species- and grade-specific estimates of digestion coefficients (DCS) and species-specific recovery rates (RRS) to account for partial and complete digestion, respectively. Greater than 98\% of otoliths were passed within three days of consumption. RRs were smallest for Atlantic salmon smolts $(\mathrm{RR}=$ $0.306, \mathrm{SE}=0.031)$ and increasingly larger for sandeels $(\mathrm{RR}=$ 0.494, $\mathrm{SE}=0.017)$, flatfish $(\mathrm{RR}=0.789, \mathrm{SE}=0.033)$, and large gadoids $(\mathrm{RR}=0.944, \mathrm{SE}=0.034-1)$. Species-specific otolith width DCs were smallest for Trisopterus species $(\mathrm{DC}=1.14, \mathrm{SE}=$ 0.015 ) and increasingly larger for flatfish ( $D C=1.27, \mathrm{SE}=$ $0.045)$, large gadoids $(\mathrm{DC}=1.32, \mathrm{SE}=0.067)$ and sandeels $(\mathrm{DC}=$ 1.57, $\mathrm{SE}=0.035)$. RRs were similar to those from gray seals (Halichoerus grypus), but harbor seal species- and gradespecific DCs were generally smaller. Differences in partial and complete digestion rates among prey species and between seal 
species highlight the importance of applying DCFs when reconstructing diet.

Key words: digestion, digestion correction factor, digestion coefficient, recovery rate, passage rate, harbor seal, diet, prey, otolith, beak. 
$[4305]-4$

The recovery of prey hard remains such as fish otoliths and cephalopod beaks from feces is widely used to estimate phocid diet (Hammond et al. 1994a, b; Bowen and Harrison 1996; Thompson et al. 1996; Tollit and Thompson 1996; Hall et al. 1998; Brown et al. 2001; Tollit et al. 2010; Bowen and Iverson 2013). Prey structures that are resistant to digestion can be collected from feces, regurgitate, stomachs and intestines. Fecal samples are relatively easy and quick to collect and despite providing little information about the defecating animal, they remain a valuable method for obtaining information on the diet of seal populations. The contents of a scat is typically representative of recent feeding within 12-48 h (Prime and Hammond 1987, Markussen 1993, Orr and Harvey 2001, Grellier and Hammond 2006, Philips and Harvey 2009) and scat analysis is therefore an appropriate technique for estimating the diet of primarily coastal species such as the harbor seal (Phoca vitulina). Fish otoliths and cephalopod beaks are species-specific in their shape. For pristine specimens, this allows accurate identification to species of these structures and for many species allometric relationships between otolith or beak size and fish or cephalopod size allow the size of ingested prey to be estimated accurately (Clarke 1986, Härkönen 1986, Leopold et al. 2001). However, when passing through the gastrointestinal 
tract of a seal, otoliths and beaks may be partially digested and thus reduced in size, and some otoliths or beaks may be completely digested. To reduce bias when reconstructing diet, digestion coefficients, and recovery rates (number correction factors) need to be applied to account for partial and complete digestion respectively (Prime and Hammond 1987; Harvey 1989; Tollit et al. 1997, 2004a, 2010; Bowen 2000; Grellier and Hammond 2006; Bowen and Iverson 2013). Failure to account for the digestion of hard prey remains using such digestion correction factors (DCFs) can lead to considerably biased estimates of diet composition and prey consumption.

Captive in vivo feeding trials have previously been conducted to quantify the extent of partial and complete digestion of otoliths and beaks consumed by harbor seals (Prime 1979, Silva and Neilson 1985, Cottrell et al. 1996, Tollit et al. 1997, Marcus et al. 1998, Phillips and Harvey 2009, Bowen and Iverson 2013). However, DCFs are limited for NE Atlantic prey species and their use when reconstructing harbor seal diet in European waters has been inconsistent; studies have used either harbor seal DCFs for a limited number of prey species (Brown et al. 2001, Pierce and Santos 2003), gray seal DCFs (Sharples et al. 2009) or no DCFs (Wilson et al. 2002). The primary aims of this study were to describe DCFs for 
$[4305]-6$

prey species commonly consumed by northeast Atlantic harbor seals including specifically passage rates of hard prey remains through the harbor seal gut and to obtain robust estimates of digestion coefficients and recovery rates to account for partial and complete digestion of species-specific prey hard parts. In presenting the results, we describe and recommend the least biased and most precise estimates of these quantities for use in field studies of the diet of harbor seals in this region. We also discuss aspects of the experiments of relevance and interest to their conduct and interpretation, and to future studies.

METHODS

Feeding experiments were conducted with harbor seals during March-April 2009 (one adult female) and August 2011-December 2012 (one juvenile male and four adult males) at the sea Mammal Research Unit (SMRU), University of St Andrews (Scotland). Seals were captured in the Eden estuary, St Andrews Bay or at Ardesier, Moray Firth and housed for up to 13 mo before being released at the sites where they were caught. At SMRU, the seals were kept in ambient temperature seawater pools and fed a multispecies diet supplemented with vitamins and iron.

For the duration of the feeding experiment, seals were housed individually in an enclosure $6.20 \mathrm{~m} \times 4.85 \mathrm{~m}$, with access 
to water (a pool $3 \mathrm{~m}$ in diameter and $1.5 \mathrm{~m}$ deep) and a dry area. Overflow and outflow water passed through a $250 \mu \mathrm{m}$ filter. The recovery rate of the system was tested using a total of 730 plastic or glass beads (2-3 $\mathrm{mm}$ diameter) that were randomly scattered in the pool enclosure and counted on recovery. In total, 17 fish and one cephalopod prey species were offered to the seals (Table 1 ). The prey fed included those species most frequently observed in the diet of harbor seals in the UK (Pierce et al. 1991, Tollit and Thompson 1996, Brown and Pierce 1998, Brown et al. 2001, Pierce and Santos 2003). Prey were obtained commercially or through collaboration with Marine Scotland Science, Aberdeen, the Pittenweem Harbour Fishermen's Mutual Association, or Jack Wright (Fleetwood) Limited. Otoliths and beaks were fed in situ in whole or gutted prey (fish obtained commercially had been gutted prior to delivery). Whole prey were fed because accurate prediction of fish length and consequently the estimated proportion by weight of each species in the diet is problematic when using an experimental otolithcarrier species (Grellier and Hammond 2005). Differences in prey availability meant that different combinations of prey were offered to each individual seal.

For a minimum of 5 d prior to the start of an experiment, each seal was fed decapitated fish to clear its digestive system 
of otoliths and beaks. During experiments, seals were offered single-species meals once a day in the late afternoon. Where prey availability allowed, seals were fed the same prey species multiple times. However, multiple meals of the same species were offered only if all otoliths previously fed of that species had been recovered or if 2 d had passed with no otoliths of that species being recovered. Meal size was kept constant for individual seals but varied across individuals depending on their size. The total length of fish and mantle length of cephalopods fed were measured to the nearest $0.1 \mathrm{~cm}$. The size of otoliths and beaks of the prey fed to the seals was estimated using the relationships given in Table S1.

The pool was drained and cleaned prior to the first experimental meal and then daily within 24 h of an experimental meal being fed (average time between feeding and draining was 18:50 h). All debris were collected from the filter during draining and cleaning, and were washed through a nest of sieves of mesh sizes $2 \mathrm{~mm}, 1 \mathrm{~mm}, 600 \mu \mathrm{m}, 335 \mu \mathrm{m}$, and $250 \mu \mathrm{m}$.

All prey remains were sorted and all otoliths and beaks retained. Otoliths and beaks were identified to species and counted. Broken otoliths and beaks were only counted if the widest or longest part of the otolith or the lower rostral length (LRL) of the beak was complete. Otolith length (OL) and 
width (OW) and cephalopod beak LRL were measured to the nearest $0.01 \mathrm{~mm}$ using digital calipers (Mitutoyo) under a binocular microscope (Kyowa optical 2D-2PL or Zeiss Stemi 2000-C). The calipers were zeroed between measurements and frequently cleaned.

Uneaten prey remains (whole prey or fish heads) were recovered from the pool daily. Lengths of undamaged fish were measured directly, whereas lengths of damaged fish were estimated from otolith measurements using regression equations (Table S2). Mean uneaten fish length was calculated from whole fish, or whole fish plus fish length estimated from either OL or OW.

For trials in which greater than 10\% of prey fed was uneaten we used nonparametric bootstrap resampling to determine whether the size distribution of fish eaten was representative of the size distribution of prey fed. In each bootstrap resample, the mean length of a randomly selected sample of fish fed, equal in size to the observed percentage of uneaten fish, was calculated. 95\% confidence intervals of the distribution of 1,000 bootstrapped fish lengths were calculated using the percentile method. If the observed mean length of uneaten fish, as calculated above, was out with the 95\% confidence interval, the trial was discarded. 
$[4305]-10$

Recovery Rates

Recovery rate (RR) was calculated as the proportion of

otoliths eaten that was recovered at the end of each feeding trial. RR would be 1 if all otoliths eaten were recovered and 0 if no otoliths were recovered. The variance of recovery rate was estimated, assuming that sample proportions were approximately normally distributed, as $p(1-p) / n$, where $p$ is the recovery rate and $n$ is the number of otoliths that were eaten. To estimate mean RR (with the appropriate measure of precision) for each experimental seal, each prey species, and each prey grouping, RRs were averaged and variances combined following Grellier and Hammond (2006). Results were first combined over all trials for each seal, giving each trial equal weight.

Results for each seal were then combined, giving each seal equal weight, to give prey-specific RRs. Finally, results for each prey species were combined into groupings of similar prey (e.g., large gadoids, flatfish, Trisopterus species).

Passage Rates

Cumulative daily passage rates were calculated for each prey species in each trial and combined as described above for recovery rates to give mean rates for each seal and each prey species. Prey species with similar taxonomy were grouped for presentation purposes. Cumulative daily passage rates were also 
calculated for groupings of species: large gadoids (Atlantic cod, Gadus morhua; haddock, Melanogrammus aeglefinus; hake, Merluccius merluccius; pollock, Pollachius pollachius; whiting, Merlangius merlangus), Trisopterus spp. (Norway pout, Trisopterus esmarkii and poor cod, Trisopterus minutus), all flatfish (dab, Limanda limanda; lemon sole, Mirostomus kitt; long rough dab, Hippoglossoides platessoides; plaice, Pleuronectes platessa; witch, Glyptocephalus cynoglossus), and all sandeels (sandeel, Ammodytes tobianus and greater sandeel, Hyperoplus lanceolatus).

Species-specific Digestion Coefficients

Digestion coefficients (mean otolith or beak size offered divided by mean otolith or beak size recovered) were calculated for fish OL and OW and squid LRL. The delta method was used to calculate the variance of each digestion coefficient (Seber 1982; Grellier and Hammond 2005, 2006). All trials from which $<10$ otoliths were recovered were excluded from further analyses, except for large gadoid trials because of the constraints of feeding large fish and maintaining constant meal size. The digestion coefficients from each trial were combined as described above for recovery rates to give mean values for each seal, each prey species, and each prey grouping. Grade-specific Digestion Coefficients 
All recovered otoliths were examined and the amount by which they had been digested was classified based on external morphological features (Leopold et al. 2001; Fig. S1). Pristine otoliths were classified as grade 1, moderately digested otoliths as grade 2, and considerably digested as grade 3 . Because of the high number of grade 3 otoliths recovered, and the high level of digestion observed in this and other studies (Tollit et al. 1997, Grellier and Hammond 2006), a further classification (grade 4, severely digested) was introduced. External morphological features used to classify a grade 4 otolith were: no visible sulcus or lobation or very worn surfaces (right column of Fig. S1). No attempt was made to classify the amount by which beaks had been digested.

Where $\geq 10$ otoliths by grade were recovered from a trial, grade-specific digestion coefficients and variances were calculated and combined in the same way as for species-specific digestion coefficients. For some species the recovery of specific grades of otoliths was very low and measurements from grade 2 and grade 3 otoliths were pooled. Grading Comparison Between Multiple Personnel

Six people were involved in grading otoliths across the course of the study. Each person had access to otolith digestion and classification reference materials (e.g., Leopold et al. 
2001 ) and received individual training. Randomized checks were conducted frequently in the first 2 wk of each person's employment. Variability in otolith grading was examined across four of the six personnel at the end of the study. One hundred whiting, sandeel, plaice, and Norway pout otoliths from scats collected in the wild were graded by each person. Differences in grade assignation were determined using a least squares regression analysis with significance at the 5\% level.

\section{RESULTS}

A total of 23,313 otoliths and beaks of 18 prey species were eaten by harbor seals during 101 whole prey feeding trials. $61.4 \%(14,306)$ of otoliths and beaks were recovered from scats. 98.1\% $(716 / 730, \mathrm{SE}=0.51 \%)$ of beads were recovered. Loss of beads from the system was observed to be though human error. Recovery Rates

For most prey species, there was considerable variability in recovery rates both among (interindividual variation) and within seals for prey fed to the same seal multiple times (intraindividual variability) (Fig. 1, Table 1). There was little variability for haddock, whiting, and Trisopterus species.

The recovery rate increased with mean undigested otolith size for each prey species within a trial up to OL $=\sim 5 \mathrm{~mm}$ and 
$[4305]-14$

OW $=\sim 3 \mathrm{~mm}$, then varied around 1 for larger otoliths, with some lower values for the largest otoliths (Fig. 2). Note that the estimated values of $R R$ in some trials were $>1$; this is discussed below.

Passage Rates

The majority of otoliths passed were recovered by the second day of feeding (i.e., within 40 h; Table 2), regardless of whether final recovery rates were high, medium or low (Table 1).

Species-specific Digestion Coefficients

Digestion coefficients varied among individual prey species (Table 3). Inter- and intra-seal variability in digestion coefficients is shown in Figure 3. Digestion coefficients calculated using OL were different from those calculated using OW. Overall, cross-trial differences were small, but the range was wider for some species than others. The relationship between digestion coefficient and mean OW or mean OL of prey offered was not significant (OL: adj. $R^{2}=-0.00065$, inverse-variance weighted regression: intercept $=1.1396 ;$ slope $=0.0035 ; P=0.333$ and OW: adj. $R^{2}=0.0154$, inverse-variance weighted regression: intercept $=1.134 ;$ slope $=0.0152 ; P=0.125)$. Note that the estimated digestion coefficient values in some trials were <1; this is discussed below. 
$[4305]-15$

Grade Specific Digestion Coefficients

Of all otoliths recovered, $1.4 \%$ were classified as grade 1 (pristine), 5.0\% as grade 2 (moderately digested), 27.8\% as grade 3 (considerably digested), and 65.9\% as grade 4 (severely digested). Because pristine otoliths have, by definition, not been affected by digestion the grade 1-specific digestion coefficient was fixed at 1.00. For Atlantic cod, haddock, and all large gadoids, measurements from grade 2 and 3 otoliths were pooled (Table 4).

As for the species-specific digestion coefficients, grade specific digestion coefficients varied among individual prey species and digestion coefficients calculated using OL were different from those calculated using OW. Standard errors were relatively small for almost all species. There was no overlap of 95\% confidence intervals for grade 3 and 4 digestion coefficients for the same species; however, confidence intervals for grades 2 and 3 typically overlapped. Grading Comparison Between Multiple Personnel

There were significant differences among personnel in the grading of Norway pout, sandeel, and whiting otoliths but not in the grading of plaice otoliths (Table S3A). In this analysis, person $1^{\prime}$ s estimates (the most experienced team member) are represented in the intercept and is the standard against which 
the others are compared. In three species (Norway pout, sandeel, and whiting) all the coefficient values were positive (Table S3B) and significant $(P \leq 0.05)$ for whiting and Norway pout. This indicates that person 1 tended to assign lower grades. The greatest difference in grading was between person 1 and person 2 (the person with the least experience). The least difference was between person 1 and person 3, who was the next most experienced grader.

\section{DISCUSSION}

We quantified the passage, recovery, and digestion of otoliths and beaks of typical prey of northeast Atlantic harbor seals and generated correction factors for estimating prey numbers and size. Such estimates improve accuracy in the assessment of diet composition, prey biomass and total consumption and inform understanding of foraging behavior, fisheries and marine predator overlap (Beverton 1985; Hammond et al. 1994a, b; Phillips and Harvey 2009; Ringrose 1993; Laake et al. 2002; Tollit et al. 1997, 2004a, b; Zeppelin et al. 2004). These estimated quantities can be used to minimize bias and maximize precision in studies of harbor seal diet in the $\mathrm{NE}$ Atlantic. Notwithstanding this, several aspects of our experiments and results require further consideration. Experimental Anomalies 
This study produced a number of experimental anomalies that warrant closer examination.

Recovery rates $>1$ were calculated for a few individual trials: $\operatorname{cod}(n=2)$, whiting $(n=2)$, haddock $(n=1)$, Norway pout $(n=1)$ and poor cod $(n=2)$. Recovery rates $>1$ should, of course, be impossible. They likely occurred because some recovered otoliths had been in the stomachs of fish that were fed in the trials; so-called secondary prey/ingestion. The majority of the fish fed were not gutted in order to mimic ingestion of prey in the wild. This resulted in mean recovery rates slightly $>1$ for Norway pout, poor cod, and haddock (Table 1).

It is possible that secondary ingestion may have positively biased estimated recovery rates. Applying positively biased recovery rates in a field study would under-correct for complete digestion. However, the impact on estimated diet composition is difficult to predict because it would depend on the amounts of different prey species in the diet and the relative positive bias in species-specific recovery rates.

For a small number of prey species, some grade- or speciesspecific digestion coefficients were <1 (Table 3, 4) which should, of course, be impossible. For species-specific digestion coefficients, this occurred only for pollock and red gurnard, 


$$
[4305]-18
$$

which are minor prey species in the diet of harbor seals in the NE Atlantic (e.g., Wilson 2014). For grade-specific digestion coefficients, this occurred only for sandeels and Trisopterus spp. There are a number of possible explanations for these anomalous results.

First, all otoliths and beaks may not have been correctly graded or measured. Multiple personnel were involved in the grading and measuring of otoliths/beaks in this study and the grading of otoliths is to some extent subjective. Differences were evident in grading categorization among personnel and this was particularly dependent on experience level (see below). Some measurement error could have occurred but there is no reason to think that this could have led to a tendency for digestion coefficients to be biased in this way.

Second, the need to use regression equations to establish the otolith sizes of the fish fed in the experimental trials introduced estimation error. This error should be symmetrical but if, by chance, otoliths that were smaller than predicted by the regression were digested less than average, the resulting estimated digestion coefficient could be $>1$ simply as a result of estimation error.

Third, smaller otoliths may be eroded and completely digested at greater rates than larger otoliths. Although we 
show, on average, that larger otoliths do not have significantly larger digestion coefficients than smaller otoliths, this may still be a contributing factor to some estimated digestion coefficients being $>1$. Harvey (1989) suggested that otoliths that are small, thin or encased in a thinner cranium or optic capsule may be more susceptible to complete digestion. If smaller otoliths did have a higher probability of being completely digested in our experimental trials, the backcalculated mean undigested size of otoliths remaining would be larger than the mean size fed which could lead to negative bias in digestion coefficient estimation. There was variation in the size of prey fed in each trial so this may have occurred to some extent in our experiments.

Applying negatively biased digestion coefficients in a field study would undercorrect for partial digestion. However, as is the case for recovery rates, the impact on estimated diet composition is difficult to predict because it would depend on the amounts of different prey species in the diet and the relative negative bias in species-specific digestion coefficients. Feeding Behavior of Seals

Feeding method has been shown to affect otolith digestion in captive gray seals, Halichoerus grypus (Grellier and Hammond 
$[4305]-20$

2005) so otoliths/beaks were fed in situ in whole or gutted prey in this study. The seals used in the experiments were generally willing to eat a varied diet; however, some individuals were more selective in their feeding choices than others. The way in which seals consumed prey in the experiments varied depending on prey size. Small prey $(<25 \mathrm{~cm})$ were typically ingested underwater while larger prey were brought to the surface and some very large $(>65 \mathrm{~cm})$ prey were left untouched by the seals. Some large prey (Atlantic salmon, Atlantic cod and flatfish) were ripped into small pieces before ingestion and seals were observed to struggle without success to consume whole the heads of large prey (Atlantic salmon and cod). Some heads were torn into pieces during consumption and otoliths possibly lost or crushed. In the wild this could also lead to some otoliths not being consumed. The nonconsumption of very large prey and the breaking up of long or wide prey during feeding is likely a morphological limitation linked to mouth-gape size or, as in odontocetes, the size of the pharynx limiting the largest size of prey that can be consumed whole (MacLeod et al. 2007).

If the heads of some large prey are not consumed or are broken up in the wild, otoliths will be lost resulting in bias in estimates of diet composition and prey consumption. The "all structure" technique is a prey identification method that can be 
used to partially correct for such bias. By using all structures in the scat prey can be identified that previously would not have been counted and can aid in improving recovery rates (Olesiuk et al. 1990, Cottrell et al. 1996, Brown and Pierce 1998, Cottrell and Trites 2002, Phillips and Harvey 2009, Gibble and Harvey 2015). However, it is challenging to incorporate this information within a robust quantitative analysis of the size and number of otoliths and beaks recovered from scats.

$$
\text { Differences in wild and captive seals' food intake rate, }
$$

meal composition, and activity state, and consequent effects on digestion rates are to be expected (Prime and Hammond 1987, Pierce et al. 1991, Bowen 2000, Tollit et al. 2004a, Casper et al. 2006, Phillips and Harvey 2009). In this study only single species meals were fed to seals and rates of consumption and activity were not measured. Further work to explore how some of these complexities could be taken into account are desirable. Passage Rates

In this study the majority of otoliths and beaks were passed within 2-3 d. Harbor seal diet composition estimated using scat analysis is thus likely to be representative of the true diet of this species which has average foraging trip durations ranging of a few days. Studies in the United Kingdom have found average trip lengths of harbor seals to vary from $1 \mathrm{~d}$ 
$[4305]-22$

in the Thames estuary, southeast England to $4.5 \mathrm{~d}$ in the Moray Firth, northeast Scotland (Sharples et al. 2012). Foraging trip duration should be explored in other studies to investigate the likely representativeness of diet inferred from scat analysis. Recovery Rates

Otoliths greater than $5 \mathrm{~mm}$ in length and $3 \mathrm{~mm}$ in width were recovered at consistently high rates. However, for smaller sized otoliths there was a marked decline in otolith recovery (Fig. 2) . These relationships are driven by species-specific differences in complete digestion of otoliths and, as expected, recovery rates were greater for prey species with relatively large, robust otoliths. This is consistent with other studies, which show that large otoliths are less likely to be completely digested (Tollit et al. 1997, 2003; Grellier and Hammond 2005, 2006). There is the potential for considerable bias in estimated diet composition if species-specific differences in recovery rates are not used, in particular, the importance of small fish is likely to be underestimated (Bowen 2000).

Digestion Coefficients

In agreement with other studies (Murie and Lavigne 1986, Tollit et al. 1997, Grellier and Hammond 2006), we found that the amount by which an otolith is digested is species-specific. Experimental trials to explore variation in digestion 
coefficients as a function of prey size were not conducted. However, by feeding prey of a size range representative of that which harbor seals have been found to eat in the wild (Sharples et al. 2009, Wilson 2014), we have incorporated prey size variability into our estimated digestion coefficients. Furthermore, we found no significant relationship between digestion coefficient and otolith size.

The estimated coefficients of variation of species- and grade-specific digestion coefficients were smaller for ow than for OL in almost all cases (Table 3, 4). Using otolith width to correct the size of otoliths recovered from scats collected in the wild would therefore tend to result in more precise estimates. One notable exception is that Atlantic cod has a markedly smaller CV for OL than for OW (Tables 3, 4) and overall results show that otolith length is the better measurement for cod, as also found for gray seals (Hammond and Grellier 2006). For herring, estimated fish size was sensitive to the choice of DC. When seals were fed herring during the trials they tended to vomit or to show symptoms of diarrhea; this may be a reason why the results for herring were inconsistent. A comparison of digestion coefficients for harbor seals shows that the species-specific DC generated by Tollit et al. (1997) provide the most realistic estimates of fish size and we 
recommend that this value should be used in diet estimation analysis and not the estimates from our experiments. Grade-specific Digestion Coefficients

External morphological features to grade the degree of digestion of otoliths and the application of grade-specific digestion coefficients have previously been used to improve estimates of prey biomass (Tollit et al. 1997, 2004a; Grellier and Hammond 2006). The use of grade-specific DCs has two advantages. First, differences in digestion rates are expected between wild and captive seals (Prime and Hammond 1987, Pierce et al. 1991, Bowen 2000, Tollit et al. 2004a, Casper et al. 2006, Phillips and Harvey 2009) and application of gradespecific DCs reduces bias introduced as a result of differences in activity, meal size/composition, etc. Second, grade-specific DCs improve precision in estimating fish size and thus in estimates of diet composition.

However, there are also potential disadvantages. Grading of otoliths is partially subjective, so some variation among graders is to be expected even with the consistent levels of training, access to the same reference materials and the collaborative work atmosphere implemented in our study. Perhaps unsurprisingly, we found technical experience to be a particular source of variation. In situations where multiple personnel are 
grading and measuring otoliths in a diet project we recommend that the batches of otoliths they process are chosen randomly from experiments and also from scats collected from haul-out sites. This will avoid a single individual working on material from a single region and/or season and diffuse any individual grading/measuring variability and possible bias.

The effects of variation in digestion grading in otoliths have not previously been explored but a limited comparison of the use of species-specific VS. grade-specific digestion coefficients revealed only minor differences in estimates of diet composition for NE Atlantic harbor seals (Wilson 2014). Nevertheless, reducing bias and increasing precision are important, especially if results are used to inform management (e.g., Hammond and Wilson 2016; Wilson and Hammond 2016). Using grade-specific DCs does achieve this, even if there is some variability among graders and the effects may be relatively small, and we recommend their use in diet studies based on scat analysis.

Cross-study Comparisons

Recovery rates in this study were comparable to those for gray seals (Grellier and Hammond 2005) but were consistently higher than those reported by Tollit et al. (1997) for harbor seals. Our mean species-specific digestion coefficients were 
$[4305]-26$

similar overall compared to those of Tollit et al. (1997). However, our grade-specific digestion coefficients were smaller than those previously reported for both harbor and gray seals (Tollit et al. 1997, Grellier and Hammond 2006). Feeding method may account for differences in harbor seal studies. Grellier and Hammond (2005) showed that otoliths were more digested in experiments where seals were presented otoliths or heads inside a "carrier" species, resulting in greater digestion coefficients than those from in situ experiments. Despite some prey speciesspecific differences, the passage rates we report are comparable with those from studies of gray seals (Grellier and Hammond 2006) and Pacific harbor seals (Phillips and Harvey 2009). Differences in physiology and food processing strategies, e.g., delayed digestion (Sparling et al. 2007) between these species may account for differences in rates of otolith erosion.

\section{AcKnowledgments}

We thank Iain Gibb and Craig Davis (Marine Scotland Science, Aberdeen), Iain Semple (Howietoun Fishery, University of Stirling), Pittenweem Harbour Fishermen's Mutual Association and Jack Wright (Fleetwood) Ltd. for their help in obtaining fish; Mardik Leopold (Wageningen-IMARES) and Tero Härkönen (Swedish Museum of Natural History) for providing the otolith and fish size data and Begoña Santos (Instituto Español de 
Oceanografía, Centro Oceanográfico de Vigo, Spain) and Graham Pierce (University of Aberdeen, Oceanlab, Newburgh, Aberdeenshire, AB41 6AA, U.K.) for providing the lower rostral length and mantle length data used to construct some of the regressions; John Watkins (Conservation Research Ltd.), Caya Sievers for assistance with otolith and beak analysis and Mel Froude, Mia Kent, Chris McKnight, Ryan Milne, Alicia Widmer, Simon Moss, Donald Malone, and the diet team volunteers for assistance with experimental work. This work was carried out under UK Home Office licenses (60/4009 and 60/3303) and with support from Marine Scotland and Scottish Natural Heritage $(\mathrm{SNH})$.

\section{LITERATURE CITED}

Beverton, R. J. H. 1985. A review of the effects of regime shifts on the production domains in the eastern North Pacific Ocean. Fish and Fisheries 3:95-113.

Bowen, W. D. 2000. Reconstruction of pinniped diets: Accounting for complete digestion of otoliths and cephalopod beaks. Canadian Journal of Fisheries and Aquatic Sciences 57:898905.

Bowen, W. D., and G. D. Harrison. 1996. Comparison of harbour seal diets in two inshore habitats of Atlantic Canada. Canadian Journal of Zoology 74:125-135. 
$[4305]-28$

Bowen, W. D., and S. J. Iverson. 2013. Methods of estimating marine mammal diets: A review of validation experiments and sources of bias and uncertainty. Marine Mammal Science $29: 719-754$

Brown, E. G., and G. J. Pierce. 1998. Monthly variation in the diet of harbour seals in inshore waters along the southeast Shetland (UK) coastline. Marine Ecology Progress Series $167: 275-289$

Brown, E. G., G. J. Pierce, J. R. G. Hislop and M. B. Santos. 2001. Interannual variation in the summer diets of harbour seals Phoca vitulina at Mousa, Shetland (UK). Journal of the Marine Biological Association of the United Kingdom $81: 325-337$

Casper, R. M., N. J. Gales, M. A. Hindell and S. M. Robinson. 2006. Diet estimation based on an integrated mixed prey feeding experiment using Arctocephalus seals. Journal of Experimental Marine Biology and Ecology 328:228-239. Clarke, M. R. 1986. A handbook for the identification of cephalopod beaks. Clarendon Press, Oxford, U.K. Cottrell, P. E., and A. W. Trites. 2002. Classifying prey hard part structures recovered from fecal remains of captive Steller sea lions (Eumetopias jubatus). Marine Mammalogy $18: 525-539$ 
Cottrell, P. E., A. W. Trites and E. H. Miller. 1996. Assessing the use of hard parts in feces to identify harbour seal prey: Results of captive-feeding trials. Canadian Journal of Zoology 74:875-880.

Gibble, C. M., and J. T. Harvey. 2015. Food habits of harbor seals (Phoca vitulina richardii) an indicator of invasive species in San Francisco Bay, California. Marine Mammal Science 31:1014-1034.

Grellier, K., and P. S. Hammond. 2005. Feeding method affects otolith digestion in captive gray seals: Implications for diet composition estimation. Marine Mammal Science 21:296306 .

Grellier, K., and P. S. Hammond. 2006. Robust digestion and passage rate estimates for hard parts of grey seal (Halichoerus grypus) prey. Canadian Journal of Fisheries and Aquatic Science 63:1982-1998.

Hall, A. J., J. Watkins and P. S. Hammond. 1998. Seasonal variation in the diet of harbour seals in the south-western North Sea. Marine Ecology Progress Series 170:269-281. Hammond, P. S., and K. Grellier. 2006. Grey seal diet composition and prey consumption in the North Sea. Final Report to Department for Environment, Food and Rural Affairs. 54 pp. Available from Sea Mammal Research Unit, 
University of St Andrews, Fife KY16 8LB, Scotland, U.K. Hammond, P. S., and L. J. Wilson. 2016. Grey seal diet composition and prey consumption. Scottish Marine and Freshwater Science $7(20) .47$ pp.

Hammond, P. S., A. J. Hall and J. H. Prime. 1994a. The diet of grey seals around Orkney and other islands and mainland sites in north-eastern Scotland. Journal of Applied Ecology $31: 340-350$

Hammond, P. S., A. J. Hall and J. H. Prime. 1994b. The diet of grey seals in the Inner and Outer Hebrides. The Journal of Applied Ecology 31:737-746.

Härkönen, T. 1986. Guide to the otoliths of the bony fishes of the northeast Atlantic. Danbiu Aps. Biological Consultants, Hellrup, Denmark.

Harvey, J. 1989. Assessment of errors associated with harbour seal (Phoca vitulina) faecal sampling. Journal of Zoology 219:101-111.

Laake, J. L., P. Browne, R. L. DeLong and H. R. Huber. 2002. Pinniped diet composition: A comparison of estimation models. Fisheries Bulletin 100:434-477.

Leopold, M. F., C. J. D. van Damme, C. J. M. Philipart and C. J. N. Winter. 2001. Otoliths of North Sea fish - fish identification key by means of otoliths and other hard 
parts. CD ROM. Version 1.0. ETI (Expert Centre for Taxonomic Identification), University of Amsterdam, Amsterdam, The Netherlands.

MacLeod, C. D., J. S. Reidenberg, M. Weller, M. B. Santos, J. Herman, J. Goold and G. J. Pierce. 2007. Breaking symmetry: The marine environment, prey size and the evolution of asymmetry in cetacean skulls. The Anatomical Record $290: 539-545$.

Marcus, J., W. D. Bowen and J. Eddington. 1998. Effects of meal size on otolith recovery from fecal samples of gray and harbor seal pups. Marine Mammal Science 14:789-802.

Markussen, N. H. 1993. Transit time of digesta in captive harbour seals (Phoca vitulina). Canadian Journal of Zoology $71: 1071-1073$

Murie, D. J., and D. M. Lavigne. 1986. Interpretation of otoliths in stomach content analysis of phocid seals: quantifying fish consumption. Canadian Journal of Zoology $64: 1152-1157$

Olesiuk, P. F., M. A. Bigg, G. M. Ellis, S. J. Crockford and R. J. Wigen. 1990. An assessment of the feeding habits of harbour seals (Phoca vitulina) in the strait of Georgia British Columbia based on scat analysis. Canadian Technical Report of Fisheries and Aquatic Sciences No. 1730. 135 pp. 
$[4305]-32$

Orr, A. J., and J. T. Harvey. 2001. Quantifying errors associated with using faecal samples to determine the diet of California sea lion (Zalophus californianus). Canadian Journal of Zoology 79:1080-1087.

Phillips, E. M., and J. T. Harvey. 2009. A captive feeding study with the Pacific harbor seal (Phoca vitulina richardii): Implications for scat analysis. Marine Mammal Science $25: 373-391$

Pierce, G. J., and M. B. Santos. 2003. Diet of harbour seals (Phoca vitulina) in Mull and Skye (Inner Hebrides, western Scotland). Journal of the Marine Biological Association of the United Kingdom 83:647-650.

Pierce, G. J., P. R. Boyle and J. S. W. Diack. 1991. Identification of fish otoliths and bones in feces and digestive tracts of seals. Journal of Zoology 224:320-328. Prime, J. H. 1979. Observations on the digestion of some gadoid fish otoliths by a young common seal. ICES CM 1979/N:14. International Council for the Exploration of the Sea, Copenhagen, Denmark.

Prime, J. H., and P. S. Hammond. 1987. Quantitative assessment of gray seal diet from fecal analysis. Pages 165-181 in A. C. Huntley, D. P. Costa, G. A. J. Worthy and M. A. Castellini, eds.). Approaches to marine mammal energetics. 
Special Publication Number 1, Society for Marine Mammalogy. Ringrose, T. J. 1993. Bone counts and statistics: A critique. Journal of Archaeological Science 20:121-157.

Seber, G. A. F. 1982. The estimation of animal abundance and related parameters. Charles Griffin and Company, London, $\mathrm{U} \cdot \mathrm{K}$.

Sharples, R. J., B. Arrizabalaga and P. S. Hammond. 2009. Seals, sandeels and salmon: Diet of harbour seals in St Andrews Bay and the Tay Estuary, southeast Scotland. Marine Ecology Progress Series 390:265-276.

Sharples, R. J., S. E. Moss, T. A. Patterson and P. S. Hammond. 2012. Spatial variation in foraging behaviour of a marine top predator (Phoca vitulina) determined by a large-scale satellite tagging program. PLoS ONE 7:e37216.

Silva, J. D., and J. D. Neilson. 1985. Limitations of using otoliths recovered in scats to estimate prey consumption in seals. Canadian Journal of Fisheries and Aquatic Sciences $42: 1439-1442$.

Sparling, C. E., M. A. Fedak and D. Thompson. 2007. Eat now, pay later? Evidence of deferred food-processing costs in diving seals Biology Letters 3:95-99.

Thompson, P. M., B. J. McConnell, D. J. Tollit, A. Mackay, C. Hunter and P. A. Racey. 1996. Comparative distribution, 


$$
[4305]-34
$$

movements and diet of harbour seals and grey seals from Moray Firth, N.E. Scotland. Journal of Applied Ecology $33: 1572-1584$.

Tollit, D. J., and P. M. Thompson. 1996. Seasonal and betweenyear variations in the diet of harbour seals in the Moray Firth, Scotland. Canadian Journal of Zoology 74:1110-1121.

Tollit, D. J., M. J. Steward, P. M. Thompson, G. J. Pierce, M. B. Santos and S. Hughes. 1997. Species and size differences in the digestion of otoliths and beaks: Implications for estimates of pinniped diet composition. Canadian Journal of Fisheries and Aquatic Science 54:105-119.

Tollit, D. J., M. Wong, A. J. Winship, D. A. Rosen and A. W. Trites. 2003. Quantifying errors associated with using prey skeletal structures from fecal samples to determine the diet of Steller's sea lion (Eumetopias jubatus). Marine Mammal Science 19:724-744.

Tollit, D. J., S. G. Heaslip, T. G. Zeppelin, R. Joy, K. A. Call and A. W. Trites. 2004 a. A method to improve size estimates of walleye pollock (Theragra chalcogramma) and Atka mackerel (Pleurogrammus monoterygius) consumed by pinnipeds: Digestion correction factors applied to bones and otoliths recovered in scats. Fishery Bulletin 102:498508 . 
Tollit, D. J., S. G. Heaslip and A. W. Trites. 2004b. Sizes of walleye Pollock (Theragra chalcogramma) consumed by the eastern stock of Steller sea lions (Eumetopias jubatus) in Southeast Alaska from 1994 to 1999. Fishery Bulletin $102: 522-532$

Tollit, D. J., G. J. Pierce, K. A. Hobson, W. D. Bowen and S. J. Iverson. 2010. Diet. Pages 191-221 in I. L. Boyd, W. D. Bowen and S. J. Iverson, eds. Marine mammal ecology and conservation: A handbook of techniques. Oxford University Press, Oxford, U.K.

Wilson, L. J. 2014. The diet and feeding ecology of harbour seals around Britain. Ph.D. thesis, University of st Andrews, st Andrews, U.K. Available at http://hdl.handle.net/10023/6554.386 pp. Wilson, L. J., and P. S. Hammond. 2016. Harbour seal diet composition and diversity. Scottish Marine and Freshwater Science 7 (21). $86 \mathrm{pp}$.

Wilson, S. C., G. J. Pierce, C. M. Higgins and M. J. Armstrong. 2002. Diet of the harbour seals Phoca vitulina of Dundrum Bay, north-east Ireland. Journal of the Marine Biological Association of the UK 82:1009-1018.

Zepplin, T. K., D. J. Tollit, K. A. Call, T. J. Orchard and C. J. Gudmundson. 2004. Sizes of walleye Pollock (Theragra 
$[4305]-36$

chalcogramma) and Atka mackerel (Pleurogrammus

monopterygius) consumed by the western stock of Steller sea

lions (Emetopias jubatus) in Alaska from 1998 to 2000.

Fishery Bulletin 102:509-521.

Received: 3 July 2016

Accepted: 2 June 2017

SUPPORTING INFORMATION

The following supporting information is available for this article online at http://

Table S1. Regressions used to infer the size of otoliths and beaks of the prey items fed to seals.

Table S2. Regressions used to infer the size of otoliths and beaks of the prey items fed to seals.

Table S3. Summary of the linear model results for examining variation in the grading of otoliths across laboratory personnel. Table S3A shows the analysis of variance. Table S3B shows the coefficient estimates and their significance (*).

Figure S1. Images in the left column of pristine (grade 1 , upper image), moderately digested (grade 2, lower left image) and considerably digested (grade 3, lower right image) otoliths and in the right column severely digested (grade 4) otoliths. Such images were used as a guide to classify otoliths by the level of digestion. Images of grade 1, 2, and 3 otoliths were 
taken from Leopold et al. (2001). Dab, whiting and, Norway pout have been presented as examples from the main prey groups fed. 
$[4305]-38$

Figure 1. Feeding trial recovery rates for (A) large gadoids, (B) flatfish, and (C) other species showing intra- and inter-seal variability. Each symbol represents a different seal. Figure 2. Recovery rate plotted against mean undigested otolith length (A) and width (B). Each point represents the recovery rate of a prey species from a single trial.

Figure 3. Inter- and intra-seal variation in digestion coefficients for each trial. Each symbol represents a different seal. Species-specific digestion coefficients by individual feeding trial are displayed for (A) large gadoid otolith length, (B) flatfish otolith length, (C) other species otolith length, (d) large gadoid otolith width, (e) flatfish otolith width, (f) other species otolith width.

1 Corresponding author (e-mail: lindswilsonhastiedgmail.com). 


$$
[4305]-39
$$

Table 1. Details of the experimental prey consumed and recovered. Mean RR is the prey-specific recovery rate; the proportion of otoliths/ beaks eaten that was recovered. RRs and variances were averaged over all trials for each seal and then across seal giving each trial and then each seal equal weight. A value of 1 means that all otoliths/beaks eaten were recovered. Where RR > 1 (haddock, poor cod, Norway pout, all Triscopterus spp.) a RR value of 1 should be used in estimates of diet of wild pinnipeds as $R R>1$ is an experimental anomaly (see Discussion). NCF is the number correction factor that was calculated as the inverse of the recovery rate (Bowen 2000).

\begin{tabular}{|c|c|c|c|c|c|c|c|c|c|c|}
\hline \multirow[b]{2}{*}{ Common name } & \multirow[b]{2}{*}{ Scientific name } & \multicolumn{2}{|c|}{ Length $(\mathrm{cm})$} & \multicolumn{2}{|c|}{ No. of otoliths/ beaks } & \multicolumn{2}{|l|}{ Mean } & \multirow[b]{2}{*}{$\mathrm{NCF}$} & \multicolumn{2}{|c|}{ No. of } \\
\hline & & $\operatorname{Min}$ & Max & eaten & recovered & $\mathrm{RR}$ & $\mathrm{SE}$ & & seals & trials \\
\hline $\mathrm{Dab}$ & Limanda limanda & 10.2 & 33 & 585 & 415 & 0.755 & 0.04 & 1.379 & 3 & 5 \\
\hline Lemon sole & Microstomus kitt & 15.6 & 32.1 & 210 & 83 & 0.474 & 0.06 & 2.44 & 2 & 3 \\
\hline Long rough dab & Hippoglossoides platessoides & 8.6 & 23.7 & 438 & 386 & 0.887 & 0.02 & 1.133 & 2 & 2 \\
\hline Plaice & Pleuronectes platessa & 13.9 & 36.4 & 492 & 403 & 0.854 & 0.04 & 1.219 & 6 & 9 \\
\hline Witch & Glyptocephalus cynoglossus & 24.6 & 43.8 & 68 & 66 & 0.976 & 0.02 & 1.025 & 2 & 2 \\
\hline All flatfish & & 8.6 & 43.8 & 1,793 & 1,353 & 0.789 & 0.03 & 1.439 & 6 & 21 \\
\hline Atlantic cod & Gadus morhua & 13 & 60.9 & 232 & 211 & 0.881 & 0.09 & 1.204 & 3 & 11 \\
\hline Haddock & Melanogrammus aeglefinus & 11.5 & 40.6 & 486 & 485 & 1.005 & 0 & 0.995 & 3 & 9 \\
\hline Hake & Merluccius merluccius & 45.1 & 54.1 & 26 & 23 & 0.893 & 0.06 & 1.136 & 1 & 2 \\
\hline Pollock & Pollachius pollachius & 43.6 & 55.2 & 8 & 8 & 1 & 0 & 1 & 1 & 1 \\
\hline Whiting & Merlangius merlangus & 11.5 & 36.7 & 1,229 & 1,180 & 0.94 & 0.03 & 1.071 & 6 & 14 \\
\hline All large gadoids & & 11.5 & 60.9 & 1,981 & 1,907 & 0.944 & 0.03 & 1.081 & 6 & 37 \\
\hline
\end{tabular}


[4305]-40

\begin{tabular}{|c|c|c|c|c|c|c|c|c|c|c|}
\hline Greater sandeel & Hyperoplus lanceolatus & 18.3 & 33.4 & 544 & 266 & 0.6 & 0.02 & 2.421 & 2 & 2 \\
\hline Sandeel & Ammodytes tobianus & 7.5 & 22.1 & 13,235 & 5,692 & 0.389 & 0.01 & 3.704 & 5 & 10 \\
\hline All sandeels & & 7.5 & 33.4 & 13,779 & 5,958 & 0.494 & 0.02 & 3.062 & 5 & 12 \\
\hline Norway pout & Trysopterus esmarkii & 9.3 & 19.9 & 3,440 & 3,477 & 1.026 & 0 & 0.98 & 6 & 8 \\
\hline Poor cod & Trysopterus minutus & 7.8 & 23.7 & 1,171 & 1,186 & 1.008 & 0 & 0.993 & 5 & 7 \\
\hline Trisopterus spp. & & 7.8 & 23.7 & 4,611 & 4,663 & 1.017 & 0 & 0.986 & 6 & 15 \\
\hline Herring & Clupea harengus & 18.8 & 29.8 & 377 & 140 & 0.428 & 0.07 & 2.697 & 4 & 8 \\
\hline Red gurnard & Chelidonichthys cuculus & 21.6 & 35.2 & 82 & 47 & 0.58 & 0.08 & 1.741 & 1 & 2 \\
\hline Salmon smolt & Salmo salar & 13.8 & 18.9 & 448 & 137 & 0.306 & 0.03 & 3.31 & 2 & 2 \\
\hline Squid & Loligo forbesii & 60 & 272 & 117 & 98 & 0.837 & 0.102 & 1.233 & 3 & 3 \\
\hline
\end{tabular}


Table 2. Percentage of the total number of otoliths and beaks recovered, calculated per day. The approximate number of hours after feeding is $16 \mathrm{~h}$ for day 1 then $+24 \mathrm{~h}$ for each subsequent day.

\begin{tabular}{|c|c|c|c|c|c|c|c|c|c|c|c|c|c|c|}
\hline \multirow[b]{2}{*}{ Prey } & \multicolumn{14}{|c|}{ Day } \\
\hline & 1 & 2 & 3 & 4 & 5 & 6 & 7 & 8 & 9 & 10 & 11 & 12 & 13 & 14 \\
\hline Flatfish & 67.6 & 87 & 98.6 & 99.2 & 99.5 & 99.5 & 99.8 & 99.8 & 99.9 & 100 & 100 & 100 & 100 & 100 \\
\hline Large gadoids & 73.2 & 96.2 & 99.7 & 100 & 100 & 100 & 100 & 100 & 100 & 100 & 100 & 100 & 100 & 100 \\
\hline Sandeels & 46.2 & 91.7 & 99.6 & 99.7 & 99.8 & 99.9 & 99.9 & 100 & 100 & 100 & 100 & 100 & 100 & 100 \\
\hline Trisopterus spp. & 47.5 & 92.2 & 99.5 & 100 & 100 & 100 & 100 & 100 & 100 & 100 & 100 & 100 & 100 & 100 \\
\hline All fish & 56.1 & 92.1 & 98.8 & 99.7 & 99.9 & 99.9 & 100 & 100 & 100 & 100 & 100 & 100 & 100 & 100 \\
\hline Squid & 56.7 & 79.5 & 81.6 & 81.6 & 81.6 & 82.3 & 82.3 & 82.3 & 99 & 99 & 99 & 99 & 99 & 100 \\
\hline
\end{tabular}


$[4305]-42$

Table 3: Species-specific digestion coefficients (DC) for harbor seals. Where DC < 1 (OL; Pollock, red gurnard) a DC value of 1 should be used in estimates of diet of wild pinnipeds as DC $<1$ is an experimental anomaly (see Discussion) .

\begin{tabular}{|c|c|c|c|c|c|c|}
\hline \multirow[b]{2}{*}{ Prey species } & \multirow[b]{2}{*}{$\mathrm{DC}$} & \multirow[b]{2}{*}{$\mathrm{SE}$} & \multirow[b]{2}{*}{$\mathrm{CV}$} & \multicolumn{3}{|c|}{ Number of } \\
\hline & & & & Seals & Trials & $\begin{array}{l}\text { Otoliths } \\
\text { recovered }\end{array}$ \\
\hline \multicolumn{7}{|l|}{ Otolith length } \\
\hline Dab & 1.28 & 0.035 & 0.028 & 3 & 5 & 383 \\
\hline Lemon sole & 1.22 & 0.112 & 0.092 & 2 & 3 & 57 \\
\hline Long rough dab & 1.18 & 0.023 & 0.02 & 2 & 2 & 367 \\
\hline Plaice & 1.17 & 0.048 & 0.041 & 6 & 9 & 358 \\
\hline Witch & 1.09 & 0.033 & 0.03 & 2 & 2 & 61 \\
\hline All flatfish & 1.19 & 0.05 & 0.042 & 6 & 21 & 1226 \\
\hline Atlantic cod & 1.24 & 0.066 & 0.053 & 3 & 11 & 150 \\
\hline Haddock & 1.17 & 0.038 & 0.032 & 3 & 9 & 376 \\
\hline Hake & 1.93 & 0.172 & 0.089 & 1 & 2 & 14 \\
\hline Pollock & 0.98 & 0.028 & 0.028 & 1 & 1 & 5 \\
\hline Whiting & 1.69 & 0.09 & 0.053 & 5 & 12 & 537 \\
\hline All large gadoids & 1.4 & 0.079 & 0.056 & 6 & 35 & 1082 \\
\hline Greater sandeel & 1.61 & 0.048 & 0.03 & 2 & 2 & 213 \\
\hline Sandeel & 1.28 & 0.02 & 0.016 & 5 & 10 & 5097 \\
\hline All sandeels & 1.45 & 0.034 & 0.024 & 5 & 12 & 5310 \\
\hline Norway pout & 1.18 & 0.013 & 0.011 & 6 & 8 & 3364 \\
\hline
\end{tabular}


[4305]-43

Poor cod
Trisopterus spp.
Herring
Red gurnard
Salmon smolt
Squid (lower
Otolith width
Dab
Lemon sole
Long rough dab
Plaice
All flatfish
Atlantic cod
Haddock
Hake
Pollock
Whiting
All large gadoids
Greater sandeel
Sandeel
All sandeels
Norway pout
Poor cod
Trisopterus spp.
Herring

\begin{abstract}
1.17
\end{abstract}
1.17

1.16

0.99

1.27

1. 12

1.35

1.32

1.22

1.18

1.27

1.23

1.23

1.8

1.1

1.25

1.32

1.75

1.4

1.57

1.13

1.14

1.14

1.3
0.016

0.013

0.044

0.034

0.029

0.041

0.037

0.053

0.035

0.081

0.024

0.041

0.045

0.063

0.024

0.144

0.071

0.033

0.067

$$
0.049
$$

$$
0.022
$$

0.035

0.012

0.018

0.015

0.058
0.026

0.062

0.019

0.035

0.036

0.051

0.02

0.08

0.065

0.027

0.051

0.028

0.015

0.023

0.011

0.016

0.013

0.044
1138

4502

87

30

112

98

414

80

385

395

1340

210

485

23

8

1180

1906

266

5687

5953

3476

1186

4662

139 
[4305]-44

Red gurnard

Salmon smolt
1.04

1.24

$$
0.037
$$

0.033

0.036

0.026

42

136 


$$
[4305]-45
$$

Table 4. Grade-specific digestion coefficients (DC) for harbor seals. Where DC < 1 (OL and OW Grade 2; sandeel, all sandeel, poor cod, Norway pout, all Trisopterus spp. grade 2) a DC value of 1 should be used in estimates of diet of wild pinnipeds as DC < 1 is an experimental anomaly (see Discussion).

\begin{tabular}{|c|c|c|c|c|c|c|c|}
\hline \multirow[b]{2}{*}{ Prey species } & \multirow[b]{2}{*}{ Grade } & \multirow[b]{2}{*}{$\mathrm{DC}$} & \multirow[b]{2}{*}{$\mathrm{SE}$} & \multirow[b]{2}{*}{$\mathrm{CV}$} & \multicolumn{2}{|c|}{ Number of } & \multirow{2}{*}{$\begin{array}{l}\text { No. of otoliths } \\
\text { recovered }\end{array}$} \\
\hline & & & & & seals & trials & \\
\hline \multicolumn{8}{|l|}{ Otolith length } \\
\hline \multirow[t]{3}{*}{ Dab } & 2 & 1.09 & 0.052 & 0.048 & 1 & 2 & 28 \\
\hline & 3 & 1.18 & 0.033 & 0.028 & 3 & 5 & 143 \\
\hline & 4 & 1.45 & 0.075 & 0.052 & 3 & 4 & 205 \\
\hline \multirow[t]{2}{*}{ Lemon sole } & 3 & 1.12 & 0.076 & 0.068 & 1 & 1 & 16 \\
\hline & 4 & 1.45 & 0.137 & 0.095 & 2 & 3 & 37 \\
\hline \multirow[t]{2}{*}{ Long rough dab } & 3 & 1.07 & 0.019 & 0.018 & 2 & 2 & 246 \\
\hline & 4 & 1.48 & 0.047 & 0.032 & 2 & 2 & 119 \\
\hline \multirow[t]{3}{*}{ Plaice } & 2 & 1.03 & 0.019 & 0.019 & 1 & 1 & 27 \\
\hline & 3 & 1.02 & 0.052 & 0.051 & 2 & 3 & 85 \\
\hline & 4 & 1.32 & 0.07 & 0.053 & 3 & 3 & 94 \\
\hline \multirow[t]{2}{*}{ Witch } & 3 & 1 & 0.032 & 0.032 & 1 & 1 & 13 \\
\hline & 4 & 1.1 & 0.036 & 0.032 & 2 & 2 & 46 \\
\hline \multirow[t]{3}{*}{ All flatfish } & 2 & 1.06 & 0.036 & 0.034 & 2 & 3 & 55 \\
\hline & 3 & 1.08 & 0.042 & 0.039 & 3 & 12 & 503 \\
\hline & 4 & 1.36 & 0.073 & 0.054 & 3 & 14 & 501 \\
\hline Atlantic cod & $2+3$ & 1.15 & 0.053 & 0.046 & 3 & 7 & 30 \\
\hline
\end{tabular}




\begin{tabular}{|c|c|c|c|c|c|c|c|}
\hline & 4 & 1.31 & 0.046 & 0.035 & 3 & 9 & 115 \\
\hline \multirow[t]{2}{*}{ Haddock } & $2+3$ & 1.05 & 0.033 & 0.031 & 3 & 6 & 25 \\
\hline & 4 & 1.21 & 0.023 & 0.019 & 3 & 8 & 351 \\
\hline Hake & 4 & 1.93 & 0.134 & 0.07 & 1 & 2 & 14 \\
\hline \multirow[t]{3}{*}{ Whiting } & 2 & 1.07 & 0.034 & 0.031 & 2 & 2 & 15 \\
\hline & 3 & 1.12 & 0.018 & 0.016 & 2 & 3 & 39 \\
\hline & 4 & 1.39 & 0.033 & 0.023 & 2 & 6 & 403 \\
\hline \multirow[t]{2}{*}{ All large gadoids } & $2+3$ & 1.1 & 0.043 & 0.039 & 3 & 13 & 55 \\
\hline & 4 & 1.46 & 0.059 & 0.04 & 3 & 25 & 883 \\
\hline Greater sandeel & 4 & 1.68 & 0.043 & 0.026 & 2 & 2 & 199 \\
\hline \multirow[t]{3}{*}{ Sandeel } & 2 & 0.93 & 0.02 & 0.022 & 2 & 4 & 344 \\
\hline & 3 & 1.02 & 0.032 & 0.031 & 4 & 7 & 1,275 \\
\hline & 4 & 1.4 & 0.026 & 0.018 & 4 & 8 & 2,526 \\
\hline \multirow[t]{3}{*}{ All sandeels } & 2 & 0.93 & 0.02 & 0.022 & 2 & 4 & 344 \\
\hline & 3 & 1.02 & 0.032 & 0.031 & 4 & 7 & 1,275 \\
\hline & 4 & 1.54 & 0.034 & 0.022 & 4 & 10 & 2,725 \\
\hline \multirow[t]{3}{*}{ Norway pout } & 2 & 0.91 & 0.018 & 0.02 & 2 & 3 & 60 \\
\hline & 3 & 1.01 & 0.018 & 0.018 & 3 & 4 & 915 \\
\hline & 4 & 1.22 & 0.011 & 0.009 & 3 & 4 & 1,609 \\
\hline \multirow[t]{3}{*}{ Poor cod } & 2 & 0.99 & 0.045 & 0.045 & 1 & 1 & 11 \\
\hline & 3 & 1.11 & 0.024 & 0.022 & 2 & 3 & 135 \\
\hline & 4 & 1.23 & 0.021 & 0.018 & 3 & 4 & 748 \\
\hline \multirow[t]{3}{*}{ Trisopterus spp. } & 2 & 0.95 & 0.031 & 0.033 & 2 & 4 & 71 \\
\hline & 3 & 1.06 & 0.021 & 0.02 & 3 & 7 & 1,050 \\
\hline & 4 & 1.22 & 0.016 & 0.013 & 3 & 8 & 2,357 \\
\hline \multirow{3}{*}{$\begin{array}{l}\text { Red gurnard } \\
\text { Salmon smolt }\end{array}$} & 3 & 1.01 & 0.034 & 0.034 & 1 & 2 & 23 \\
\hline & 3 & 1.12 & 0.022 & 0.02 & 2 & 2 & 35 \\
\hline & 4 & 1.37 & 0.05 & 0.036 & 2 & 2 & 73 \\
\hline
\end{tabular}




\begin{tabular}{|c|c|c|c|c|c|c|c|}
\hline \multirow[t]{3}{*}{ Dab } & 2 & 1.14 & 0.045 & 0.04 & 1 & 2 & 30 \\
\hline & 3 & 1.23 & 0.031 & 0.026 & 3 & 5 & 148 \\
\hline & 4 & 1.53 & 0.06 & 0.039 & 3 & 4 & 229 \\
\hline \multirow[t]{2}{*}{ Lemon sole } & 3 & 1.13 & 0.07 & 0.062 & 1 & 1 & 16 \\
\hline & 4 & 1.49 & 0.116 & 0.077 & 2 & 3 & 55 \\
\hline \multirow[t]{2}{*}{ Long rough dab } & 3 & 1.1 & 0.02 & 0.018 & 2 & 2 & 251 \\
\hline & 4 & 1.54 & 0.047 & 0.031 & 2 & 2 & 132 \\
\hline \multirow[t]{3}{*}{ Plaice } & 2 & 1.03 & 0.014 & 0.014 & 1 & 1 & 27 \\
\hline & 3 & 1.08 & 0.046 & 0.043 & 2 & 3 & 94 \\
\hline & 4 & 1.29 & 0.074 & 0.057 & 3 & 3 & 100 \\
\hline \multirow[t]{3}{*}{ All flatfish } & 2 & 1.09 & 0.03 & 0.027 & 2 & 3 & 57 \\
\hline & 3 & 1.14 & 0.042 & 0.037 & 3 & 12 & 523 \\
\hline & 4 & 1.46 & 0.074 & 0.051 & 3 & 14 & 566 \\
\hline \multirow[t]{2}{*}{ Atlantic cod } & $2+3$ & 1.16 & 0.059 & 0.051 & 3 & 7 & 34 \\
\hline & 4 & 1.32 & 0.068 & 0.052 & 3 & 10 & 169 \\
\hline \multirow[t]{2}{*}{ Haddock } & $2+3$ & 1.07 & 0.035 & 0.033 & 3 & 6 & 40 \\
\hline & 4 & 1.25 & 0.023 & 0.018 & 3 & 9 & 445 \\
\hline Hake & 4 & 1.8 & 0.144 & 0.08 & 1 & 2 & 23 \\
\hline \multirow{3}{*}{ Whiting } & 2 & 1.02 & 0.017 & 0.016 & 3 & 4 & 29 \\
\hline & 3 & 1.03 & 0.011 & 0.011 & 3 & 4 & 89 \\
\hline & 4 & 1.22 & 0.021 & 0.017 & 3 & 8 & 791 \\
\hline \multirow[t]{2}{*}{ All large gadoids } & $2+3$ & 1.12 & 0.047 & 0.042 & 3 & 13 & 74 \\
\hline & 4 & 1.39 & 0.061 & 0.044 & 3 & 30 & 1,431 \\
\hline Greater sandeel & 4 & 1.82 & 0.047 & 0.026 & 2 & 2 & 252 \\
\hline Sandeel & 2 & 0.95 & 0.021 & 0.022 & 2 & 4 & 359 \\
\hline
\end{tabular}


[4305]-48

\begin{tabular}{lccccccc} 
& 3 & 1.07 & 0.035 & 0.033 & 4 & 7 & 1,375 \\
All sandeels & 4 & 1.54 & 0.028 & 0.018 & 4 & 8 & 2,914 \\
& 2 & 0.95 & 0.021 & 0.022 & 2 & 4 & 359 \\
\multirow{2}{*}{ Norway pout } & 3 & 1.11 & 0.06 & 0.054 & 4 & 9 & 1,387 \\
& 4 & 1.68 & 0.038 & 0.022 & 4 & 10 & 3,166 \\
Poor cod & 2 & 0.9 & 0.019 & 0.022 & 2 & 3 & 61 \\
& 3 & 0.98 & 0.014 & 0.014 & 3 & 4 & 944 \\
\multirow{3}{*}{ Trisopterus spp. } & 4 & 1.16 & 0.01 & 0.009 & 3 & 4 & 1,636 \\
& 2 & 0.97 & 0.043 & 0.045 & 1 & 1 & 11 \\
Herring & 3 & 1.09 & 0.023 & 0.021 & 2 & 3 & 141 \\
Red gurnard & 4 & 1.19 & 0.021 & 0.018 & 3 & 4 & 773 \\
\multirow{2}{*}{ Salmon smolt } & 3 & 0.93 & 0.031 & 0.034 & 2 & 4 & 72 \\
& 4 & 1.03 & 0.018 & 0.018 & 3 & 7 & 1,085 \\
& 3 & 1.28 & 0.038 & 0.03 & 1 & 1 & 2,409 \\
& 3 & 1.02 & 0.029 & 0.028 & 1 & 2 & 18 \\
& 4 & 1.22 & 0.064 & 0.052 & 1 & 1 & 25 \\
& 3 & 1.1 & 0.025 & 0.023 & 2 & 2 & 10 \\
& 4 & 1.34 & 0.046 & 0.034 & 2 & 2 & 37
\end{tabular}



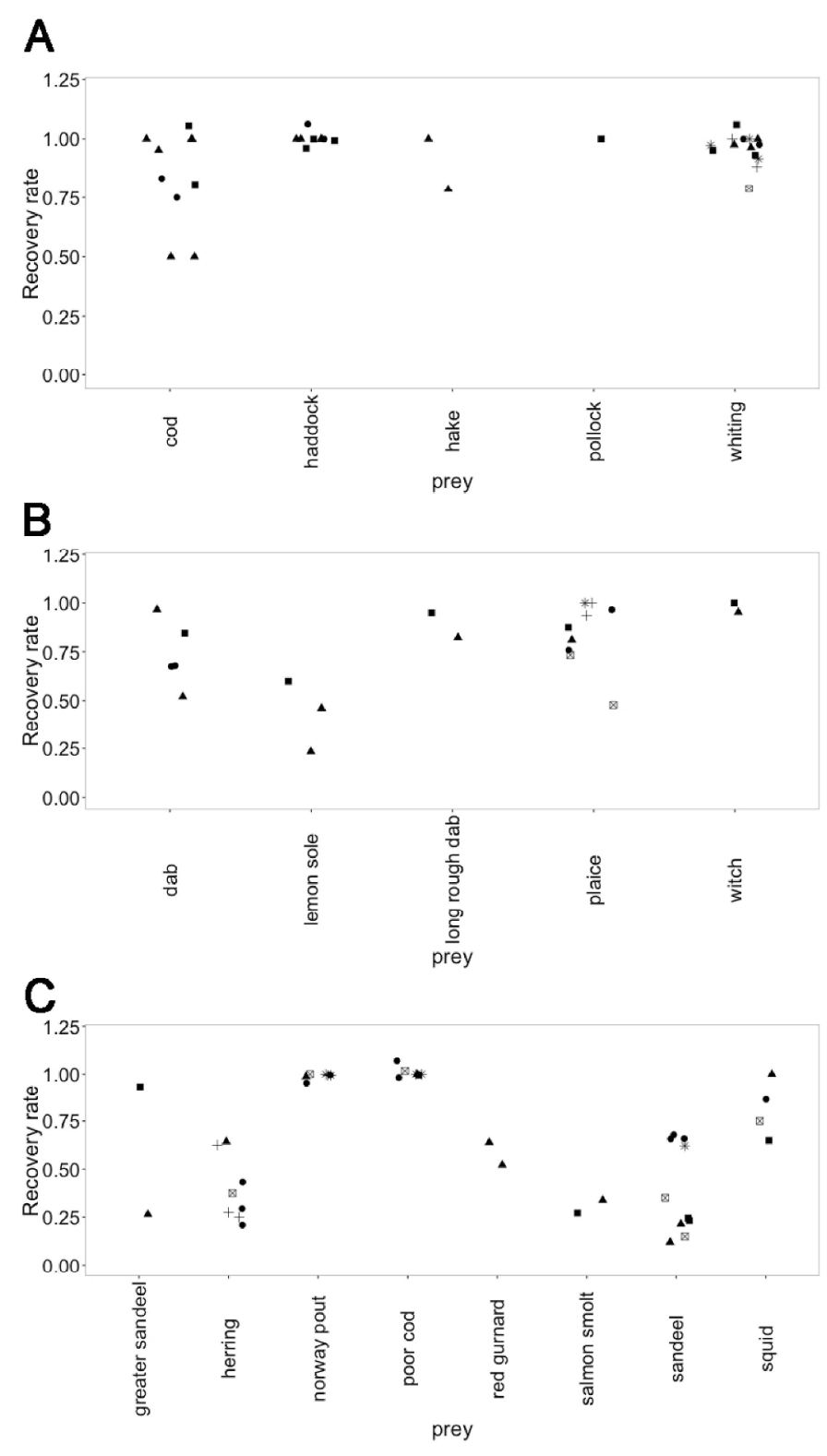

$208 \times 370 \mathrm{~mm}(300 \times 300$ DPI $)$ 

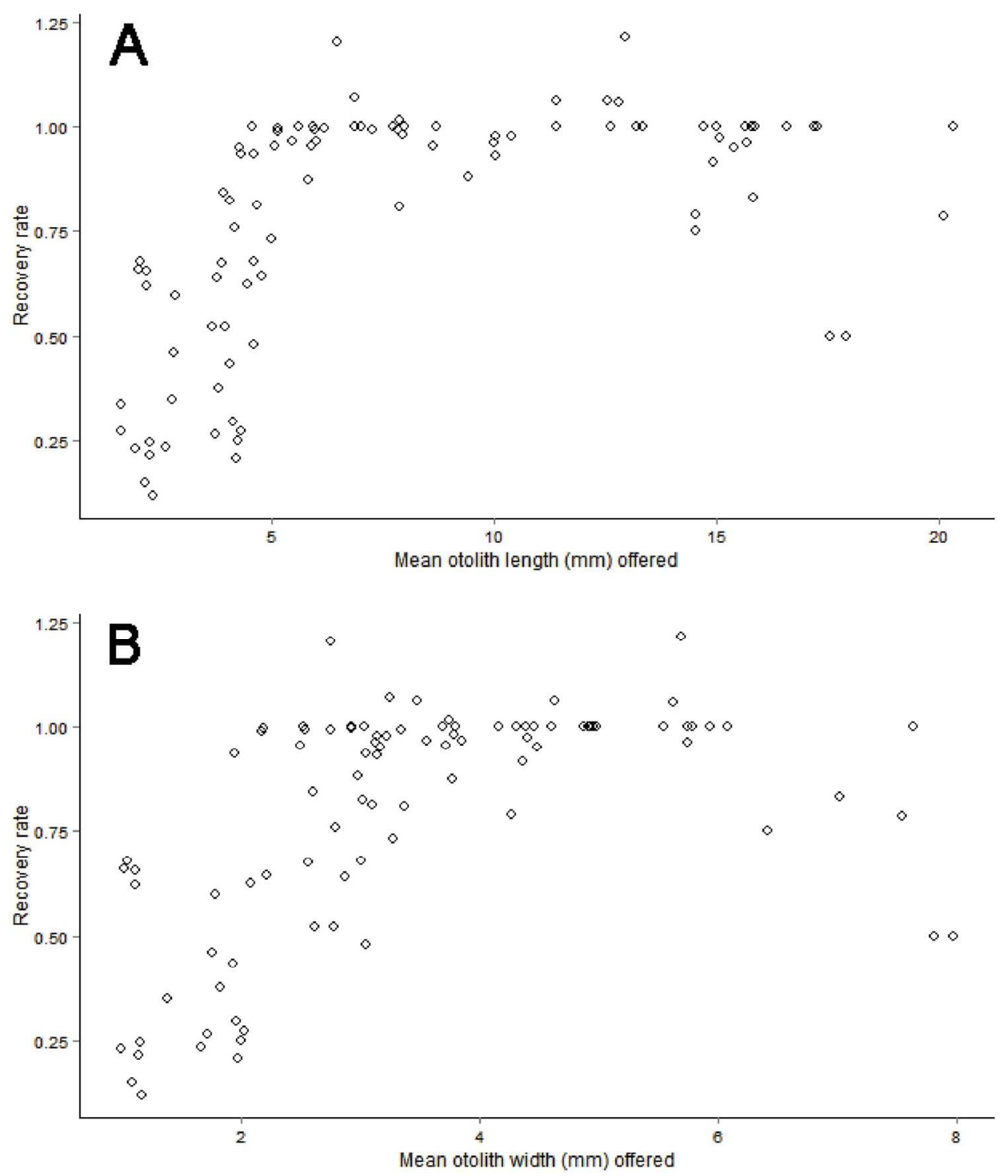

$135 \times 155 \mathrm{~mm}(300 \times 300$ DPI $)$ 
$603 \times 519 \mathrm{~mm}(600 \times 600 \mathrm{DPI})$ 
Table S1. Regressions used to infer the size of otoliths and beaks of the prey items fed to seals.

\begin{tabular}{|c|c|c|c|c|c|c|c|}
\hline Species & OL regression & $r^{2}$ & $n$ & OW regression & $r^{2}$ & $n$ & Source \\
\hline Atlantic cod & $\mathrm{OL}=0.266 \mathrm{FL}+2.306$ & 0.93 & 518 & $\mathrm{OW}=0.122 \mathrm{FL}+0.811$ & 0.96 & 547 & 1 \\
\hline Haddock & $\mathrm{OL}=0.383 \mathrm{FL}+1.560$ & 0.97 & 450 & $\mathrm{OW}=0.137 \mathrm{FL}+0.703$ & 0.96 & 469 & 1 \\
\hline Whiting & $\mathrm{OL}=0.564 \mathrm{FL}-0.198$ & 0.98 & 559 & $\mathrm{OW}=0.142 \mathrm{FL}+0.55$ & 0.96 & 637 & 1 \\
\hline Hake & $\mathrm{OL}=0.365 \mathrm{FL}+1.991$ & 0.98 & 60 & $\mathrm{OW}=0.131 \mathrm{FL}+1.046$ & 0.96 & 62 & 1 \\
\hline Pollack & $\mathrm{OL}=0.243 \mathrm{FL}+2.551$ & 0.97 & 294 & $\mathrm{OW}=0.097 \mathrm{FL}+1.066$ & 0.96 & 304 & 1 \\
\hline Norway pout & $\mathrm{OL}=0.436 \mathrm{FL}+0.028$ & 0.98 & 257 & $\mathrm{OW}=0.186 \mathrm{FL}+0.002$ & 0.98 & 257 & 1 \\
\hline Poor cod & $\mathrm{OL}=0.362 \mathrm{FL}+1.718$ & 0.95 & 267 & $\mathrm{OW}=0.178 \mathrm{FL}+0.731$ & 0.93 & 275 & 1 \\
\hline Sandeel & $\mathrm{OL}=0.185 \mathrm{FL}-0.056$ & 0.93 & 332 & $\mathrm{OW}=0.085 \mathrm{FL}+0.079$ & 0.91 & 337 & 1 \\
\hline Greater sandeel & $\mathrm{OL}=0.141 \mathrm{FL}+0.510$ & 0.96 & 399 & $\mathrm{OW}=0.057 \mathrm{FL}+0.409$ & 0.95 & 410 & 1 \\
\hline Atlantic herring & $\mathrm{OL}=0.154 \mathrm{FL}+0.386$ & 0.96 & 514 & $\mathrm{OW}=0.061 \mathrm{FL}+0.472$ & 0.93 & 541 & 1 \\
\hline European plaice & $\mathrm{OL}=0.203 \mathrm{FL}+0.486$ & 0.99 & 752 & $\mathrm{OW}=0.119 \mathrm{FL}+0.641$ & 0.97 & 787 & 1 \\
\hline Common dab & $\mathrm{OL}=0.179 \mathrm{FL}+0.734$ & 0.97 & 508 & $\mathrm{OW}=0.107 \mathrm{FL}+0.699$ & 0.95 & 513 & 1 \\
\hline Lemon sole & $\mathrm{OL}=0.091 \mathrm{FL}+0.624$ & 0.87 & 240 & $\mathrm{OW}=0.059 \mathrm{FL}+0.356$ & 0.89 & 240 & 1 \\
\hline Long rough dab & $\mathrm{OL}=0.213 \mathrm{FL}+0.477$ & 0.95 & 322 & $\mathrm{OW}=0.137 \mathrm{FL}+0.730$ & 0.91 & 338 & 1 \\
\hline Witch & $\mathrm{OL}=0.114 \mathrm{FL}+1.602$ & 0.89 & 81 & - & - & - & 2 \\
\hline Atlantic salmon & $\mathrm{OL}=0.024 \mathrm{FL}+1.715$ & 0.03 & 49 & $\mathrm{OW}=0.013 \mathrm{FL}+1.047$ & 0.01 & 49 & 3 \\
\hline Gurnard $^{\mathrm{a}}$ & $\mathrm{OL}=0.111 \mathrm{FL}+0.726$ & 0.94 & 735 & $\mathrm{OW}=0.079 \mathrm{FL}+0.697$ & 0.90 & 741 & 1 \\
\hline Squid (lower rostral length) & $\mathrm{LRL}=0.0099 \mathrm{ML}+0.807$ & 0.85 & 518 & - & - & - & 4 \\
\hline
\end{tabular}

Note: Otolith length (OL), otolith width (OW) and lower rostral length (LRL) were measured in mm; fish length (FL) and squid mantle length (ML) were measured in cm. Source data provided by: (1) M. Leopod (Wageningen-IMARES, PO Box 167, Landsdiep 4, NRL-1797 SZ Den Hoorn, Texel, The Netherlands), (2) T. Härkönen (Swedish Museum of Natural History, Box 50007, 10405 Stockholm, Sweden), (3) C. Sievers and L. J. Wilson (Sea Mammal Research Unit, Scottish Oceans Institute, University of St. Andrews, East Sands, KY16 8LB, U.K.) and (4) M. B. Santos (Instituto Español de Oceanografía, Centro Oceanográfico de Vigo, Spain) and G. J. Pierce (University of Aberdeen, Oceanlab, Newburgh, Aberdeenshire, AB41 6AA, U.K.). Sources 1 and 2 are summarized in Leopold et al. (2001) and Härkönen (1986), respectively. Sources 3 and 4 are unpublished data (December 2012).

${ }^{a}$ The gurnard regression was developed across measurements from both red and grey gurnard species. 
Table S2. Regressions used to infer the size of otoliths and beaks of the prey items fed to seals.

\begin{tabular}{llcclcc}
\hline \hline \multicolumn{1}{c}{ Species } & \multicolumn{1}{c}{ OL regression } & $r^{2}$ & $n$ & \multicolumn{1}{c}{ OW regression } & $r^{2}$ & $n$ \\
\hline Atlantic cod & $\mathrm{FL}=3.49 \mathrm{OL}-6.64$ & 0.88 & 268 & $\mathrm{FL}=7.84 \mathrm{OW}-5.51$ & 0.86 & 275 \\
Haddock & $\mathrm{FL}=2.53 \mathrm{OL}-3.27$ & 0.90 & 236 & $\mathrm{FL}=6.99 \mathrm{OW}-4.00$ & 0.90 & 240 \\
Whiting & $\mathrm{FL}=1.73 \mathrm{OL}+0.81$ & 0.79 & 303 & $\mathrm{FL}=6.74 \mathrm{OW}-2.97$ & 0.86 & 315 \\
Poor cod & $\mathrm{FL}=2.61 \mathrm{OL}-3.84$ & 0.96 & 144 & $\mathrm{FL}=5.22 \mathrm{OW}-2.98$ & 0.94 & 144 \\
Sandeel & $\mathrm{FL}=5.00 \mathrm{OL}+1.16$ & 0.86 & 170 & $\mathrm{FL}=10.92 \mathrm{OW}$ & - & 172 \\
Dab & $\mathrm{FL}=5.43 \mathrm{OL}-3.49$ & 0.88 & 261 & $\mathrm{FL}=8.88 \mathrm{OW}-5.40$ & 0.9 & 261 \\
Plaice & $\mathrm{FL}=4.85 \mathrm{OL}-2.07$ & 0.76 & 405 & $\mathrm{FL}=8.15 \mathrm{OW}-4.70$ & 0.79 & 405
\end{tabular}

Note: Otolith length (OL), otolith width (OW) were measured in $\mathrm{mm}$; fish length $(\mathrm{FL})$ was measured in $\mathrm{cm}$.

Table S3. Summary of the linear model results for examining variation in the grading of otoliths across laboratory personnel. (A) shows the analysis of variance, (B) shows the coefficient estimates and their significance $\left({ }^{*}\right)$.

(A)

\begin{tabular}{llcccc}
\hline \hline \multicolumn{1}{c}{ Species } & $\mathrm{df}$ & Sum sq & Mean sq & $F$ & $P$ \\
\hline Norway pout & 3 & 5.01 & 1.67 & 5.49 & $<0.05^{*}$ \\
Sandeel & 3 & 2.9 & 0.97 & 3.75 & $<0.05^{*}$ \\
Plaice & 3 & 0.49 & 0.16 & 1.45 & 0.22 \\
Whiting & 3 & 3.06 & 1.02 & 3.89 & $<0.05^{*}$ \\
\hline
\end{tabular}

(B)

\begin{tabular}{ccccc}
\hline \hline & Estimate & SE & $t$ & $P$ \\
\hline Norway Pout & & & & \\
Intercept & 3.49 & 0.06 & 63.29 & $<0.05^{*}$ \\
Person 2 & 0.31 & 0.78 & 3.98 & $<0.05^{*}$ \\
Person 3 & 0.17 & 0.78 & 2.18 & $<0.05^{*}$ \\
Person 4 & 0.21 & 0.78 & 2.69 & \\
Sandeel & & & & \\
Intercept & 3.53 & 0.05 & 69.52 & $<0.05^{*}$ \\
Person 2 & 0.23 & 0.07 & 3.2 & 0.21 \\
Person 3 & 0.16 & 0.07 & 2.23 & \\
Person 4 & 0.09 & 0.07 & 1.25 & 0.40 \\
Plaice & & & & 0.20 \\
Intercept & 3.89 & 0.03 & 116.7 & 0.53 \\
Person 2 & 0.04 & 0.05 & -0.84 & \\
Person 3 & 0.06 & 0.05 & -1.27 & $<0.05^{*}$ \\
Person 4 & 0.03 & 0.05 & 0.64 & $<0.05^{*}$ \\
Whiting & & & & $<0.05^{*}$ \\
Intercept & 3.61 & 0.05 & 70.48 & 2.9 \\
Person 2 & 0.21 & 0.07 & 2.49 & 2.9 \\
Person 3 & 0.18 & 0.07 & & \\
Person 4 & 0.21 & 0.07 & & \\
\hline
\end{tabular}



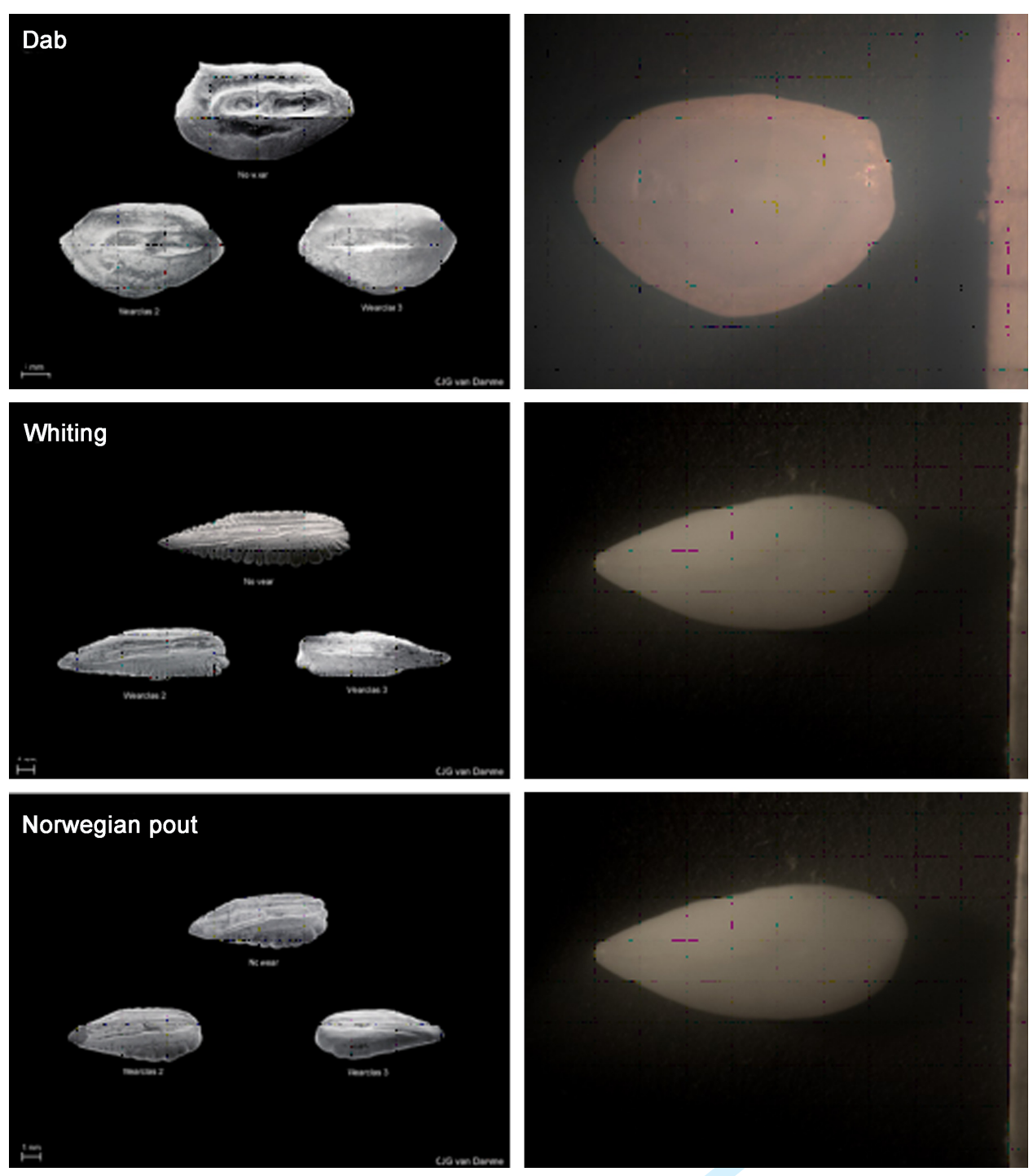

Figure S1. Images in the left column of pristine (grade 1, upper image), moderately digested (grade 2, lower left image) and considerably digested (grade 3, lower right image) otoliths and in the right column severely digested (grade 4) otoliths. Such images were used as a guide to classify otoliths by the level of digestion. Images of grade 1, 2, and 3 otoliths were taken from Leopold et al. (2001). Dab, whiting and, Norway pout have been presented as examples from the main prey groups fed. 